\title{
Causes of failure of a four-storey building and the reconstruction concept
}

\author{
Jerzy Rzeźniczak ${ }^{1}$, Zbigniew Młynarek ${ }^{2, *}$,Stawomir Gogolik ${ }^{2}$, and Joanna Michalak ${ }^{1}$ \\ ${ }^{1}$ Geotechnika Jerzy Rzeźniczak, Albańska Street 18, 60-123 Poznan, Poland \\ ${ }^{2}$ University of Life Sciences in Poznan, Wojska Polskiego Street 28, 60-637 Poznań, Poland
}

\begin{abstract}
The article presents causes of failure of a four-storey building of a complex structure. It reviews the causes related to soil features, foundation works and construction design of the facility. The article rationalizes the concept of soil improvement using the jet-grouting technology and suggests eliminating the process of flooding and damping basements of the building.
\end{abstract}

\section{Introduction}

A construction failure is a complex process influenced by several factors $[1,2]$. Complementarity of the subsoil -foundation-construction model of the facility clearly defines causes of a construction failure. These causes are the result of doubts or even construction design errors, doubts and judgements errors in soil strength and deformation parameters and errors of the implementation and exploitation proces of the facility $[1,3]$. Based on European statistics, Brandl [4] stated that between 80 and $85 \%$ of all construction failures were related to the soil. Chapman and Marcelleau conducted a significant study [5] in which they observed that approximately $50 \%$ of the analyzed failures showed discrepancies between the conditions presented in geotechnical documentation of ground investigation and actual conditions in the subsoil. The role of the afore-mentioned factors in a construction failure can vary, however, it is very rare if a construction failure is caused by all factors simultaneously and qualitative share in this process is comparable. Such case is presented in this article. Identifying individual groups of factors occurring in a building failure allowed suggesting a concept of halting this process, which is also discussed in the article.

\footnotetext{
*Corresponding Author: zbigniew.mlynarek@gmail.com
} 


\section{General description of the analyzed issues}

A church with a free-standing bell tower and a parish house was built between 2003 and 2004 in the western Ukraine.

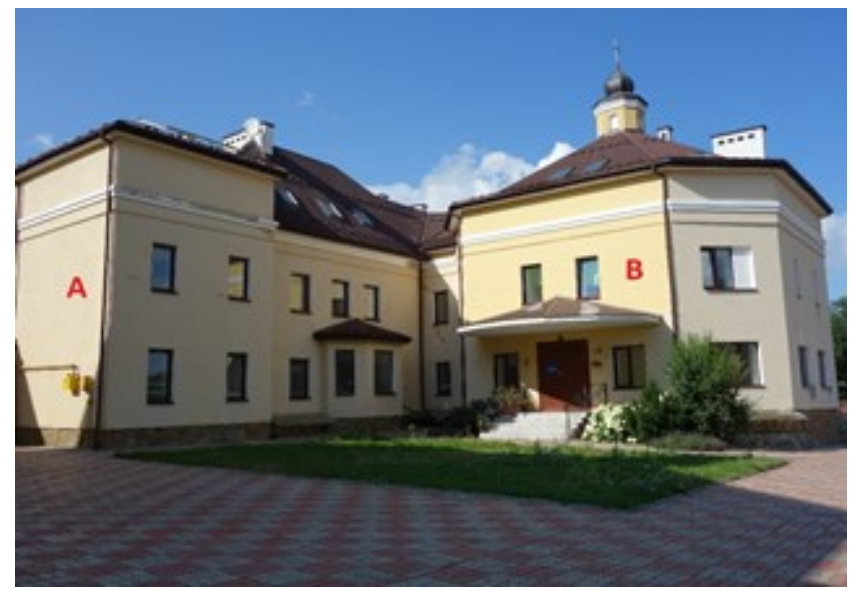

Fig. 1. Buildings' layout: A - northern part, B - southern part.

The information obtained from the on-site inspection disclosed alarming evidence of uneven settlement of the bell tower and the parish house that occurred already during their construction. After the construction had been finished, the walls and ceilings of the parish house unveiled scratches ranging between 3 and $5 \mathrm{~cm}$ in width. The scratches are also visible on the walls of the garage adjacent to part A of the parish house. The emerged cracks and scratches are still spreading. No scratches, however, were observed on the church walls. The inspection also revealed another issue vital to exploitation of the building, namely severe dampness of basement walls. In order to identify the causes of the damages the building incurred and flooding of the basement space, it was necessary to use the design and geological documentation, recommend uncovering of the foundations and perform additional cone penetration tests of the subsoil.

\section{Construction characteristic of the parish house}

The parish house consists of two parts: A - northern part - the building on the projection of an extended rectangle with a garage and part $\mathrm{B}$ - the building in the shape of an octagon (Fig. 1).

Both buildings consist of three overground storeys and one underground storey used as a fully functional service space. The construction of the buildings is supported by walls made of ceramic brick and concrete slabs built into the basement walls. The ceilings were built with reinforced concrete, hollowcore slabs without using reinforced concrete-supported external walls. The direct foundations were designed as a unit consisting of prefabricated 30centimeter thick elements of varied width: $0.80,1.00$ and $1.20 \mathrm{~m}$, loosely placed under loadbearing walls. The foundation level of both parts of the buildings varies. As far as the northern part $\mathrm{A}$ is concerned, the afore-mentioned level is usually at the depth: $5.10 \mathrm{~m} \mathrm{b.g.l.,} \mathrm{locally}$ at the depth of $3.90 \mathrm{~m}$, whereas in part B - mostly at the depth $-4.50 \mathrm{~m} \mathrm{b.g.1.} \mathrm{and} \mathrm{partly}$ deeper, at the depth $-5.10 \mathrm{~m}$ b.g.l (Fig. 2). 


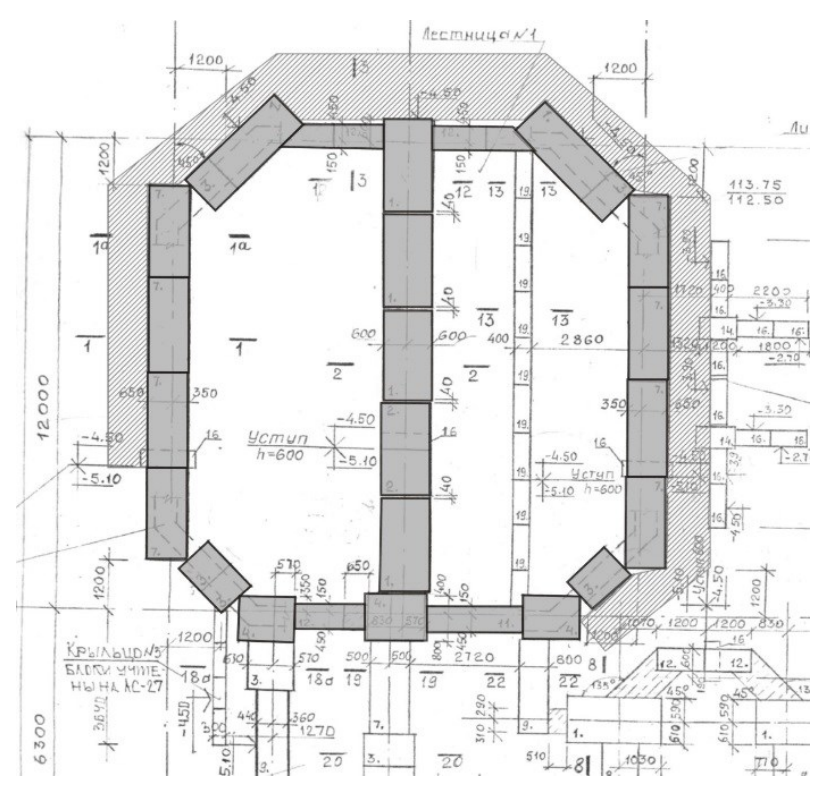

Fig. 2. Layout of prefabricated foundations of part B.

\section{Soil-water conditions of the subsoil}

The construction design of the parish house was based on the geological documentation prepared before its construction by a local company. The scope of the tests conducted for the subsoil was limited to eight $6.0 \mathrm{~m}$ deep boreholes. The laboratory tests only distinguished physical soil features. The geotechnical cross-sections showed three main ground layers found in the subsoil. The first one was non-construction embankment, the second one - the layer of mineral silty sands, the third one - the layer of mineral fine sands.

After having detected damages to the building, another two sets of documents were prepared in 2017 and 2018. To examine properties and the subsoil structure, a Ukraininan company AI $\phi$ used the results of boreholes and cone penetration tests. The laboratory test program included identification of grain-size composition and physical parameters of soil samples. Shear strength and deformation parameters of the separated soil layers were accepted according to the Ukrainian norm DRN.W.2.1-10-2009. Comparing the determined construction features and features of soil under the parish house revealed a complete lack of compliance in terms of the thickness of embankment layers, presence of organic soils and geotechnical parameters of the separated soil layers (Fig. 3). 


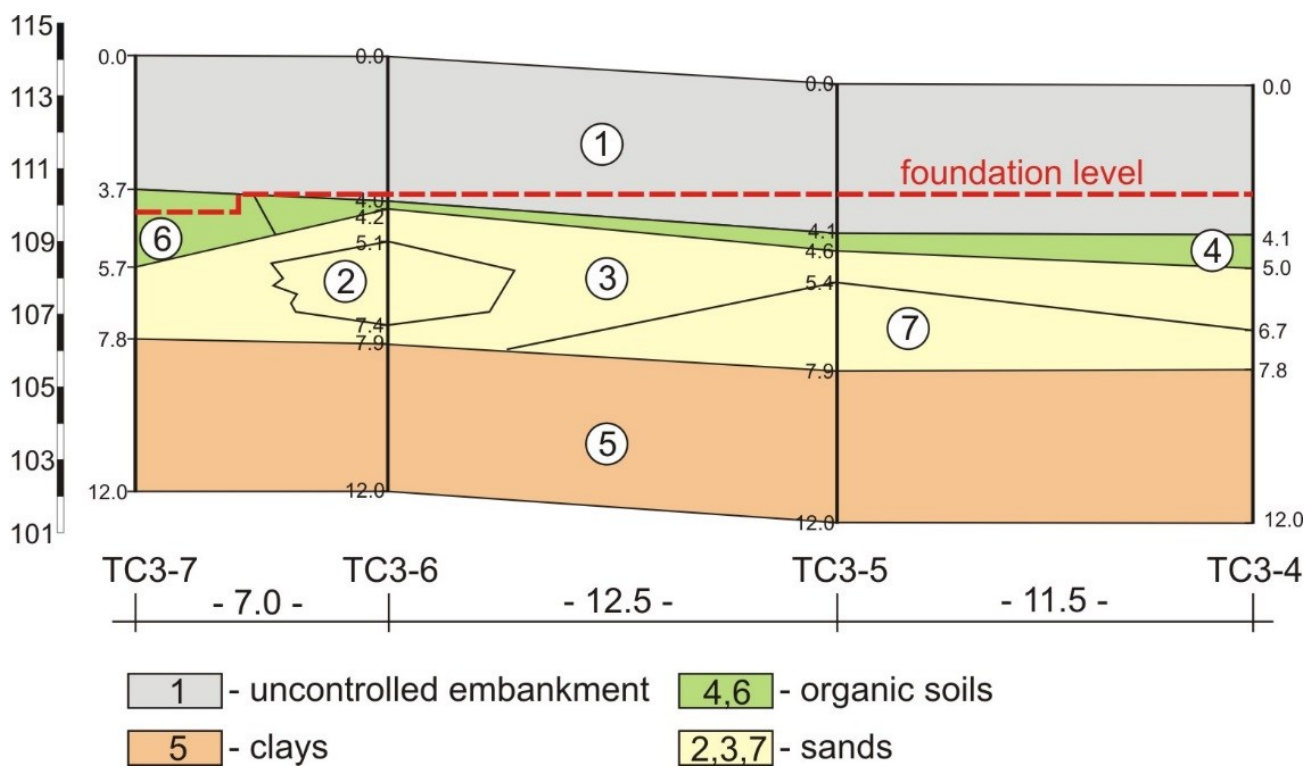

Fig. 3. Geotechnical profile of the soil.

The vital element in the assessment of how the foundation works with the subsoil is to determine the constant change in the shear strength and deformation parameters of the soil. For this purpose, the Authors of this paper have determined the above-mentioned parameters based on the cone penetration test characteristics (Fig. 4). For this study, the person conducting the test used the mechanical Begemann cone. This particular cone does not allow measuring pore pressure, thus the determined mechanical parameters of soils should be considered purely estimated (Fig. 5). The obtained results of the friction ratio - $\mathrm{R}_{\mathrm{f}}$ with depth, showed that the embankments of the surface zone are very heterogeneous and contain soils of highly deiversified grain size: from fine sands to silty sands, filled with cohesive and probably organic soils (Fig. 3). In order to determine the parameters of silty soils, ie. liquidity index, correlations and diagrams designed for soils from the territory of Poland developed for soils from the country by the HEBO Poznan company Geotechnical Department at the University of Life Sciences in Poznań, were used [6]. To change the level of density of noncohesive soil, the Jamiolkowski [7] procedure was applied employing monograms depending on normally consolidated sands. The layout presenting the changes of the level of density in the embankemnt unveils that it is not a construction embankment and is characterized by high variabiltiy of density level. 


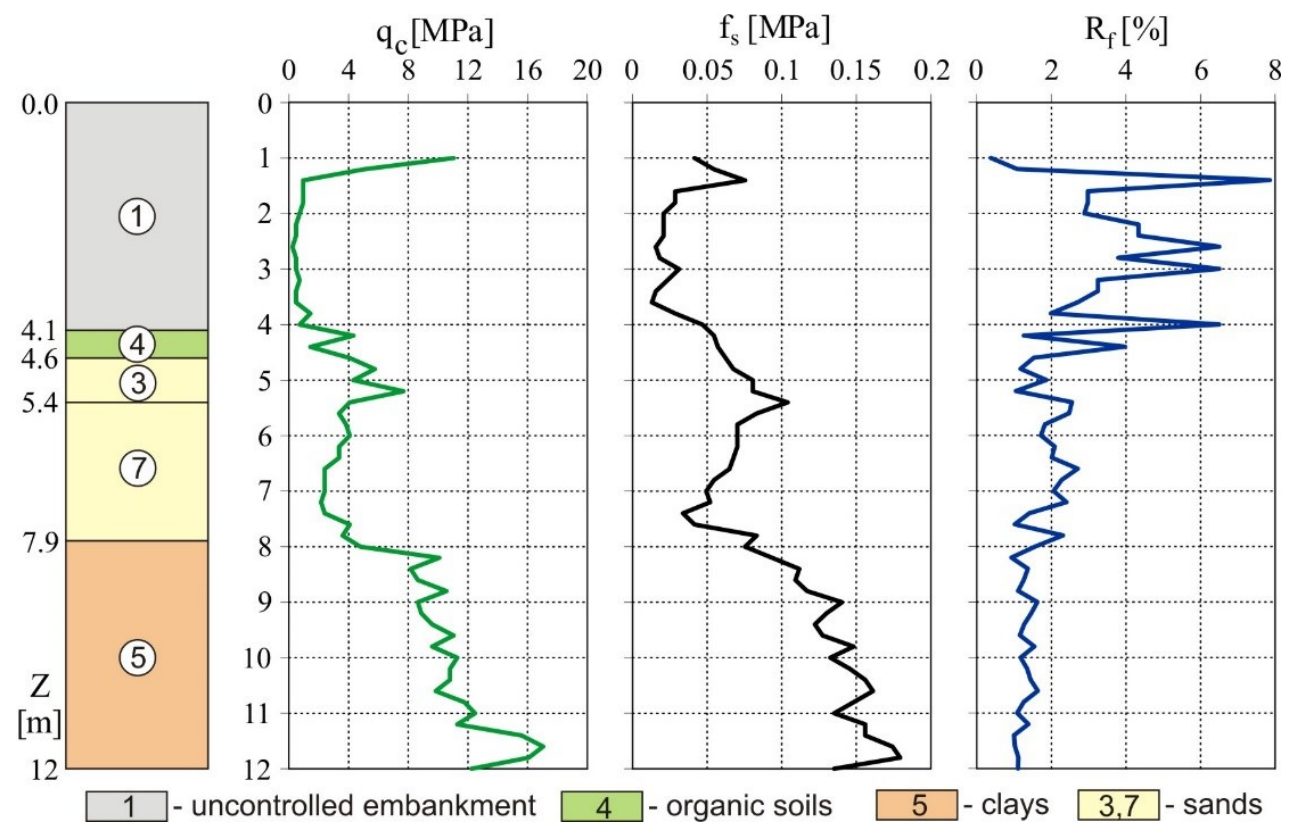

Fig. 4. Characteristics of the CPT test.

The soil parameters were determined according to the following procedures:

- Modulus of constrained deformation modulus M

In order to calculate the numeric value of constrained deformation modulus $M=M_{0}$ in the preconsolidation range, which corresponds to the oedometric modulus on particular levels of total overburden stress $\sigma_{\mathrm{v} 0}$, seperate empirical correlations of cohesive and non-cohesive soils were applied. As far as cohesive soils are concerned and layers presented on the geotechnical layout with 4, 5, 6 (Fig. 3), the formula defined by Sanglerat was applied [8].

$$
\mathrm{M}=\alpha, \mathrm{q}_{\mathrm{c}}
$$

Factor $\alpha$ for loamy sands of layer 5, which contained significant amounts of fine and silty fraction adopted 3 . For a section of loamy sands mixed with humus sands, probably organic silt (assessment based on the values of $R_{f}-$ Fig. 4) the factor value of $\alpha=2$ was adopted.

In order to determine the compressibility modulus for mineral fine and silty sands, the formula by Lunne [8], which, depending on the cone resistance value (normally consolidated soil), was applied and is as follows:

$$
\begin{aligned}
& \mathrm{q}_{\mathrm{c}}<10 \mathrm{MPa} \quad \mathrm{M}=4 \mathrm{q}_{\mathrm{c}} \\
& 10 \mathrm{MPa}<\mathrm{q}_{\mathrm{c}}<50 \mathrm{MPa} \\
& \mathrm{M}=2 \mathrm{q}_{\mathrm{c}}+20(\mathrm{MPa})
\end{aligned}
$$

For the soils in the embankment, because of high heterogeneity of grain size, modulus $\mathrm{M}$ was calculated with factor $\alpha=3$. In terms of the performed analysis, one can conclude that the values of the constrained modulus found in the documentation of AI $\phi$ range in the variability limits, which were established by means of a detailed interpretation (Fig. 5). 
Exceptionally high compliance of the assessment of moduli changes with the changes in liquidity index or density index of the soil is worth emphasizing.

- Undrained shear strength $\mathrm{s}_{\mathrm{u}}$

For cohesive soils undrained shear strength was determined according to Lunne [8]:

$$
\mathrm{s}_{\mathrm{u}}=\left(\mathrm{q}_{\mathrm{c}}-\sigma_{\mathrm{v} 0}\right) / \mathrm{Nk}
$$

For the silty sands found in the soil, in layer 4 with an admixture of organic soils, the $s_{u}$ values were calculated with the $\mathrm{N}_{\mathrm{k}}=19$ factor (Fig. 5). The determined values of $\mathrm{s}_{\mathrm{u}}$ in layer 4 classify it as soils of low shear strength according to PN-EN ISO 14688-2, whereas loamy sands of layer 5 can be classified as soils of high or medium shear strength.

- Effective friction angle $\phi^{\prime}$ of non-cohesive soil in the subsoil

To determine the effective friction angle of soil in critical state for the alluvial fine and silty sands in the subsoil, Bolton formula modified by Jamiołkowski was applied [7]. Furthermore, the obtained total friction angle values from Mayne correlations were examined [9].

Having examined the geotechnical cross-section (Fig. 3), it is apparent that the foundations of part B of the parish house were placed in the layer of organic soils and embankments of highly unfavorable strength and deformation parameters.

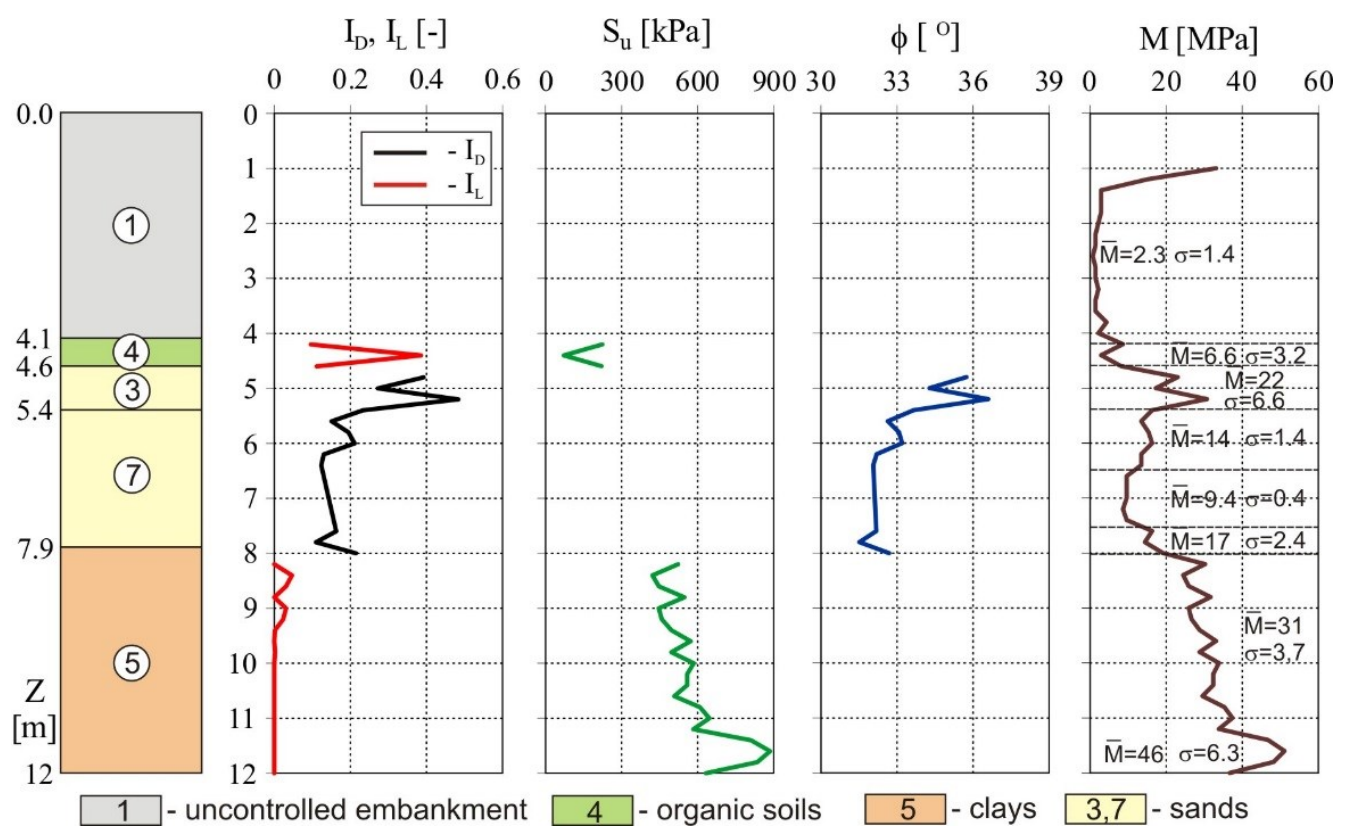

Fig. 5. Strength and deformation parameters of soil from the cone penetration tests. 


\section{Characteristics of cracks and scratches found in the building}

Cracks or scratches have not been found on the church walls, however, they have been found in both parts (northern and southern) of the parish house and garage walls. Part A of the building displays a higher concentration of such damages, which are mostly visible on the external bearing walls, internal walls and partition walls, as well as between the ceiling and the walls. The location of the documented scratches is presented in Fig. 6.

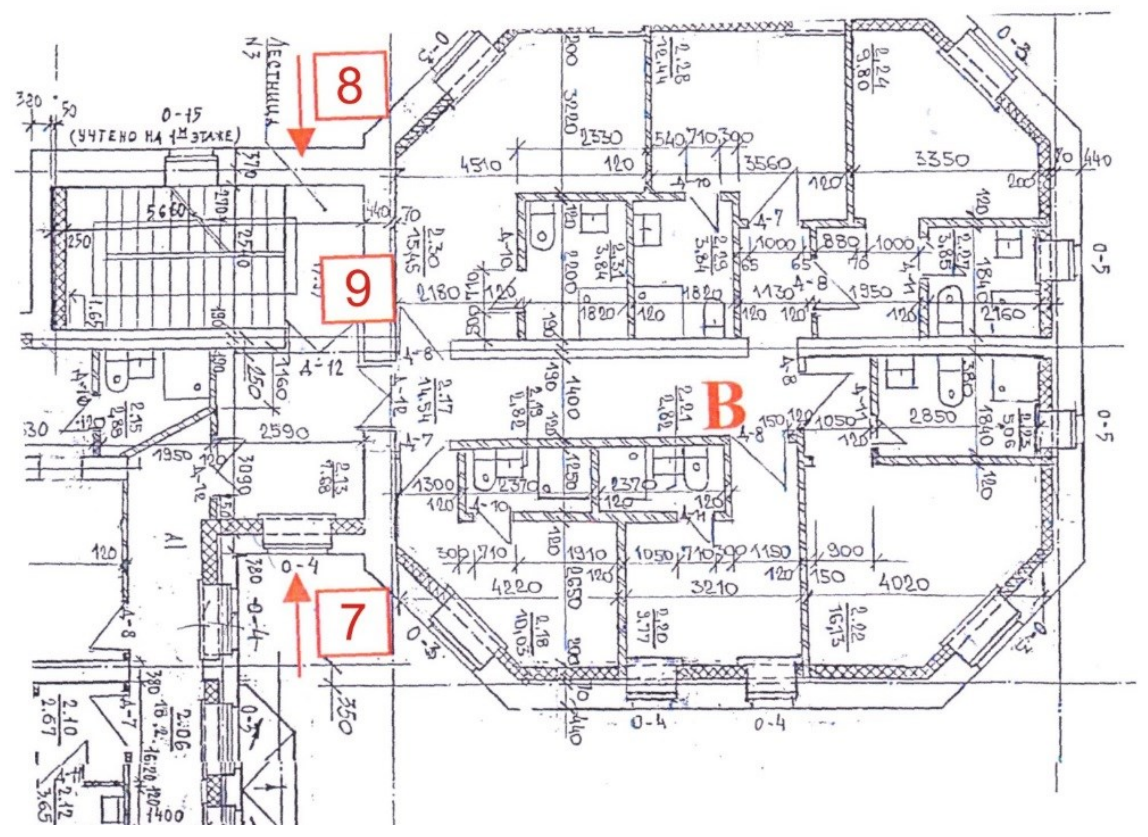

Fig. 6. Location of images 7, 8 and 9 showing scratches on the walls and basement floor.

The size of cracks and scratches varies: the gap often ranges between $10 \div 20 \mathrm{~mm}$, but locally it may amount to $40 \mathrm{~mm}$. Some of the scratches are active and spreading.

Particular attention was paid to very characteristic scratches in the area linking the northern part A and southern part B of the building (Fig. 6). The analysis of the nature and type of deformations that ensued on the structure of the linking part lead to a conclusion that both part A and part B of the building behave in a distinctive manner.

- a higher number of scratches, distributed in different places and rather moderate in size, are characteristic for the northern part A,

- the southern part B is characterized by significant settlement, which is related to the whole octagonal construction of this part of the building; settlement is diversified and the whole construction leans to the south as a result. This only proves the conclusion that soil conditions found under the building foundations are diversified. 


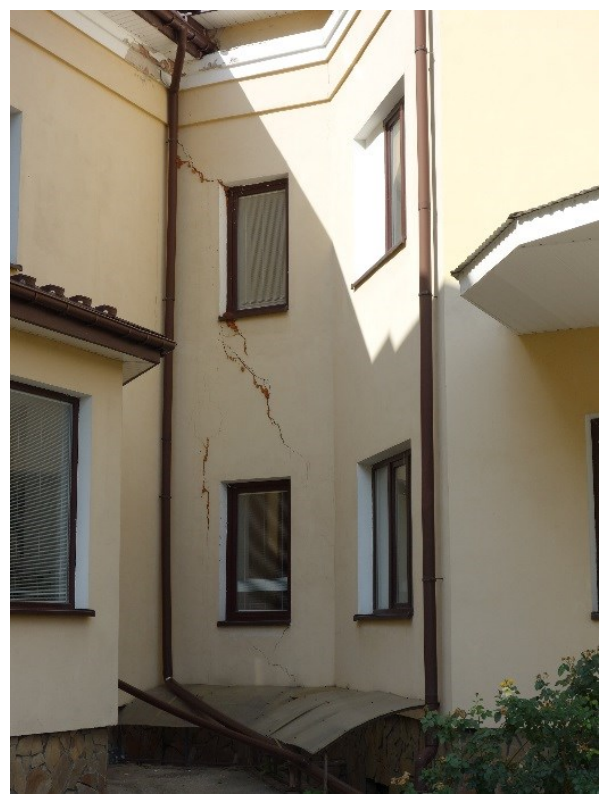

Fig. 7. Scratches on the external wall of the staircase (condition as of 09.07.2018).

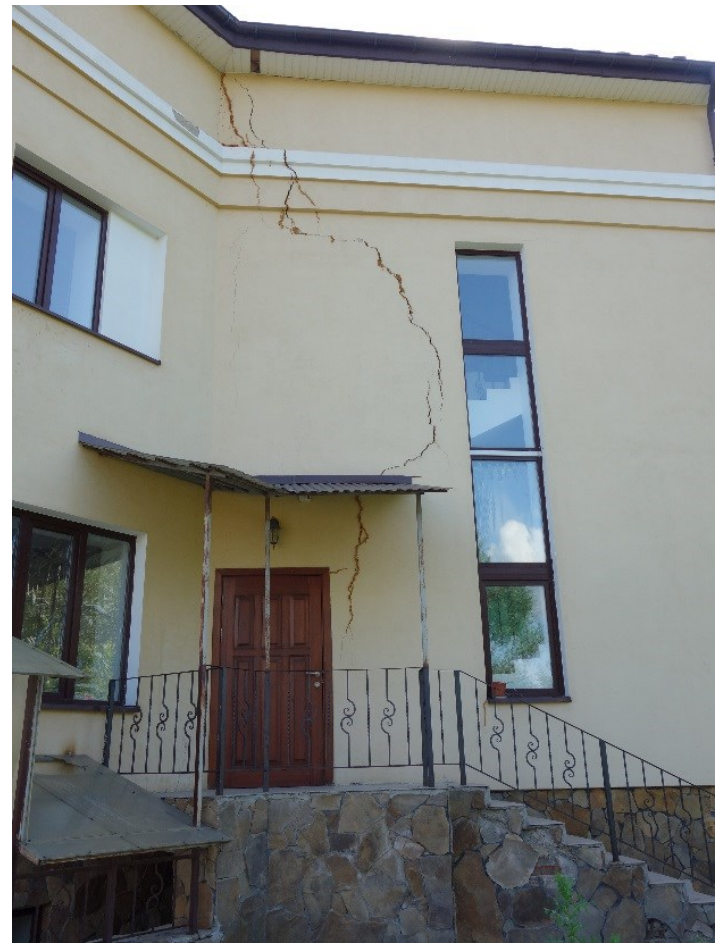

Fig. 8. Scratches of the external bearing wall of the linking part between the northern and southern part of the building (condition as of 09.07.2018). 


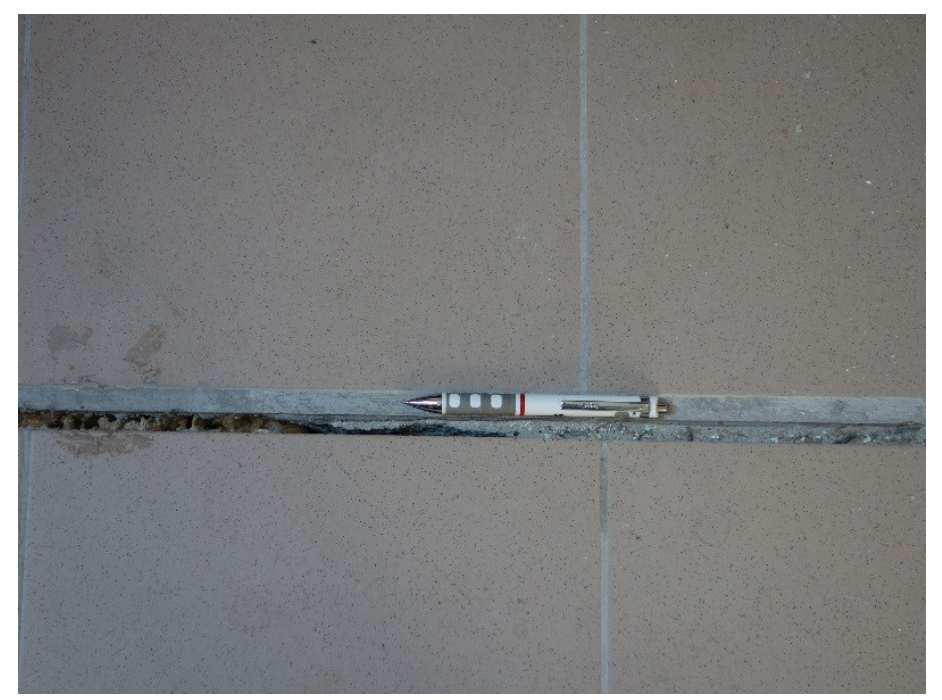

Fig. 9. Crack (approx. $30 \mathrm{~mm}$ ) found on the floor between the stairs and the ceiling (condition as of 09.07.2018).

\section{Analysis of foundation settlements of building B}

The group of factors that influenced the scratches and damages to the building walls include the size and uneven settlement of the foundations. To determine the settlement, characteristic values of load transferred by the foundations to the subsoil, which were included in the construction design of the building, were adopted. They amounted to, respectively $\sigma \ldots=288.75 \mathrm{kN} / \mathrm{m}^{2}$ under the external walls and $\sigma \ldots=262.12 \mathrm{kN} / \mathrm{m}^{2}$ under the internal wall (Fig. 2). Due to high diversification in the rigidity of the embankment layers and organic soil layers, as compared to the layer of mineral sands at an increased depth, settlement calculations included strain of layers supported by the top part of mineral sands. The structure and thickness of layers was adopted in accordance with the geotechnical design, which was adjusted using cone penetration test results. In order for the settlements to be determined, the constrained moduli, determined based on CPT characteristics, were applied (Fig. 5). The obtained amount of settlements for medium and minimal values of the compressibility moduli in the layers of the embankments and alluvial mud is presented in Table 1.

Table. 1. Overview of the determined settlements.

\begin{tabular}{|c|c|c|}
\hline \multirow{2}{*}{ Subsoil as in cone penetration test } & \multicolumn{2}{|c|}{ Settlement s [cm] for: } \\
\cline { 2 - 3 } & med. Mo & min. Mo \\
\hline CPT-4 & 8.1 & 12.7 \\
\hline CPT-5 & 11.1 & 17.7 \\
\hline CPT-6 & 6.0 & 6.0 \\
\hline
\end{tabular}


Table 1 proves that, in case of particularly cross-sections of the subsoil (where CPT were conducted), settlements are highly diversified and significant. It can be assumed that the consolidation process of the alluvial mud layer has not come to an end and seasonal changes to water conditions may contribute to further settling of the foundations.

\section{Determining the repair method, reinforcement and securing the construction of the building and improving the subsoil}

\subsection{Causes of scratches}

The article introduction discussed the causes of construction failures, emphasizing the failures with some unfavourable conditions and incidents. Such situation took place in the analyzed construction failure of the parish house. The circumstances are as follows:

- Incorrect interpretation of soil conditions in the documentation from 2002. The documentation states that the subsoil consists of mineral sands of fine mechanical parameters, which enable direct placement of the designed building. However, it turned out that the subsoil contains embankments and organic soils that do not meet the criteria of building regular and direct foundations,

- The contractors and construction supervisors did not react to clearly visible cohesive and organic soils different than the ones presented in the documentation,

- The faulty construction of the building with its placement on the heterogeneous and compressible ground, particularly:

- implementing a very original placement on prefabricated, loosely placed (not attached) foundation slabs, instead of monolithic reinforced concrete foundations,

- no need for concentrating the whole construction of the building by using: reinforced concrete foundations, reinforced concrete external walls on the level of ceilings on every storey and reinforced concrete tangs connecting foundations with the external walls,

- $\quad$ no dilatation between buildings $\mathrm{A}$ and $\mathrm{B}$.

\subsection{Concept of reinforcing the building and the soil improvement under its foundations}

The selection of concept for the building reconstruction is influenced by the distribution and character of scratches, diversification of depth at which part A and B of the buidling was placed, and diversified soil conditions under the foundations of part $\mathrm{A}$ and $\mathrm{B}$ of the building. Having examined the above factors, it was concluded that two different ways of reconstruction for both separated parts A and B of the building should be considered and developed:

- $\quad$ under building A, which is built at a greater depth, there are better soil conditions than under more shallow foundations in part B. For part A of the building, construction reinforcements are sufficient and necessary in the areas exhibiting cracks and scratches on the walls; 
- building B has got more shallow foundations, placed directly on the embankments and organic soils. In order to stabilize the building settlement, it is vital to improve the weak soil under the foundations. Conducting these works is the highest priority. Only after such improvement has been implemented under building B, can construction reinforcements in buildings $\mathrm{A}$ and $\mathrm{B}$ be built.

Nowadays, the construction practice can apply a few technologies for foundation and subsoil improvement in order to stabilize the settlement of foundations and transfer the load to the subsoil of sufficient rigidity and strength. Because of the construction of the footings, which were formed with prefabricated slabs and are supported in part B of the building on the layer of organic soils, locally $1.80 \mathrm{~m}$ thick (Fig. 3), some of the methods used to reinforce the foundations, e.g. intercepting and expanding the foundations and changing the organic subsoil cannot be applied. In such conditions, the most appropriate method is to improve the weak subsoil under the already existing foundations using the jet grouting technology, also called streaming technology. This technology forms columns from concrete-soil, formed from improved soils and concrete slurry, grouted under very high pressure amounting to $450 \div 600$ atmospheres. This method allows creating a solid support for every separately placed foundation slab.

The characteristics layout of the bearing walls and foundations along with the depth of their placement (Fig. 2) imposes several technological conditions for the improvement of the subsoil. Under the foundations of the external walls, it will not be necessary to improve the foundation fragment, which is placed deeper and on a denser soil. As far as the internal bearing wall of building B is concerned, the improvement will be constructed in the hall of the basement - without interfering monolithic stairs. An element crucial to conduct the improvement works is building a foundation trench to form a jet grouting column. The excavation cannot expose the foundation base and the bottom of the excavation should be built at the depth corresponding to the level of the basement floors. The jet grouting columns should be constructed in a skew arrangement to possibly produce full clumping of the weak soil under the already existing foundations. The first stage of the column construction should be construction of the column located under the center of individual prefabricated foundation slabs. Constructing these columns in a skew arrangement and in a hole drilled through the foundation slab may turn out to be very beneficial. A significant element in the column construction is the fact that the concrete-soil in the constructed column, before it binds (thick liquid), weakens the subsoil under the foundation. Thus, it is necessary to construct the columns in an alternating manner retaining sections of protection zones, also considering the time required for the concrete-soil to bind.

The second stage necessary to reinforce the parish house, as previously mentioned, will be reinforcing the building walls, probably with steel structural sections and rods. Such solution, however, must be subject to a separate specialist design. 


\section{Problem of dampness (flooding) of basements}

The building is located in the area of a potential flow of ground water to the nearby river. This drainage impact of the river tends to be interrupted at the time when the water level dramatically increases, when the level of ground water in the nearby river rises. During the flood of 1972, the maximum water level in the river was recorded at $1.20 \mathrm{~m}$ elevation above the basement floors. The ground water level also rises when rainwater is directed from the drain pipes of the building directly into to ground. The analysis of soil conditions revealed that for the examined soil, the level of ground water is subject to seasonal fluctuations of a relatively high amplitude. The foundations and the foundation walls during high levels of ground water are an obstacle obstructing the natural flow of water to the river causing it to build up.

To eliminate the problem of flooding of the basement spaces of the building and their convenient use, it is necessary to take preventive action to secure the basements form hazardous damping:

- eliminating hazardous rainwater drainage from roof areas directly into the subsoil near the building by creating a special rainwater sewage system that would collect the water from the drain pipes and direct it further from the buildings, preferably to a nearby river.

- creating a cicular drainage, arranged around part A and B of the building, implemented based on a specialistic design.

While determining the location of the designed drainage system, its location below the level of the basement floors and above the level of the foundations should be taken into account. Excavations built to place the drainage system should be built using small segments. It is unacceptable to build an excavation along the whole wall of the building. The placement of the drainage system will be possible after reinforcing the weak soil under the foundations of building B. The excavation built to reinforce the subsoil can be utilized to place the drainage system.

\section{Summary}

The existing scratches of the analyzed building are the result of diversified and uneven settlement of its prefabricated foundations, which were placed on weak and compressible soil. At the moment, it cannot be stated that this settlement process has fully ceased. On the contrary, one should consider its further development, since the settlement process can be triggered by factors different than load. Settlements will develop due to physical-chemical and biological properties taking place in organic soils also under the influence of seasonal fluctuations of the ground water levels. It is crucial to monitor the existing cracks. It would be preferable to install approximately 10 gypsum seals on the existing characteristic cracks, installing 8 benchmarks, installed in four corners of buildings A and B and conducting the null measurement at the very moment.

The presented emergency condition of the building is a good example of not implementing a risk management method, e.g. GeoQ in a construction design $[2,10]$. On the basis of the location of the building nearby a river and diversified soil structure, the criteria applied for this method should be included in the construction design. Then, after building the foundation trench and its acceptance, running additional soil tests can be recommended, as well as changing the concept of the building placement, thus assuring its failure-free cooperation with the soil. 


\section{References}

1. M. Van Staveren. Uncertainty and ground conditions in a risk management approach. (Herworth, Oxford, 2006)

2. Z. Młynarek. Subsoil contribution to construction failures (Proceedings of XXIV Scientific-Technical Conference on Structural Failures, Szczecin-Międzyzdroje, 2009) [in Polish]

3. G.F. Sowers. J. Geotech. Eng., 119(2) (1993)

4. H. Brandl. The civil and geotechnical engineer in society. Ethical and philosophical challenges and recommendations (The Deep Foundations Institute, Hawthorne, 2004)

5. T.J.P. Chapman, A. Marcelleau, Struct. Eng., 82 (2004)

6. Z. Młynarek, Site investigation and mapping in urban area (Proceedings of $14^{\text {th }}$ European Conference on Soil Mechanics and Geotechnical Engineering, Madrid, 2007)

7. M. Jamiolkowski, Lo Presti D.C.F., Manassero M., Evaluation of relative density and shear strength of sands frim CPT and DMT. (C.C. Ladd Symposium, M.I.T. Cambrigde Mass, 2001)

8. T. Lunne, P.K. Robertson, J.J.M. Powell, Cone Penetration Testing in Geotechnical Practice (Blackie Academic and Professional, London, 1997)

9. P.W. Mayne, In-situ test calibration for evaluating soil parameters. In-situ testing. (Proceedings of the Singapore Workshop, pp. 1-56, 2006)

10. M. van Staveren, Towards risk-driven site characterization (GeoDeelft and Deelft University of Technology, Millpress, 2008) 